\title{
EDITORIAL
}

\section{Epidemiology of tuberculosis in Europe: still a matter of deep concern}

\author{
T. Schaberg
}

Nearly one third of all human beings around the world are infected with $M$. tuberculosis. Due to primary infection or reactivation, more than 80 million new cases will occur during the nineties. Moreover, with more than 30 million deaths in this decade, tuberculosis is still the major killer among all infectious diseases [1]. Clearly, most new cases and the vast majority of all deaths are observed in developing countries in Africa and Asia [2], but, in addition, the re-emergence of tuberculosis still represents a serious threat to public health in Europe and the United States [3, 4]. For most politicians and for the media of developed countries, this seems to be a miracle since tuberculosis is widely believed to be a "dead" or at least "dying" disease. Although the epidemiological situation in Europe in 1996 seems not to be "pandemic", there is still a substantial morbidity in Europe, as reflected by an annual incidence of new cases ranging between 5 per 100,000 and $>50$ per $100,000[5,6]$. These large differences in incidence rates are important in view of the fact that there is increasing migration within Europe. The fall of the former Eastern bloc and the struggling new market economies in Eastern Europe [7], in particular, will continue to cause migration and, thus, also to increase the importation of tuberculosis from highprevalence countries to low-prevalence countries [8]. However, discussing the epidemiology of tuberculosis in Europe and organizing plans to solve the problem is extremely difficult, primarily because there is a lack of reliable epidemiological data.

This issue of the European Respiratory Journal contains a recommendation for a European surveillance system prepared by a Working Group of the World Health Organization (WHO) and the Europe Region of the International Union Against Tuberculosis and Lung Disease (IUATLD) [9]. It is nearly impossible to praise this effort adequately, since the Working Group has been able to summarize the situation in no less than 46 European countries, covering nearly the whole of Europe.

Four points presented in this report deserve to be mentioned here. Firstly, the report includes a simple and reliable definition of the cases searched for with the surveillance system by differentiating between definitive cases (confirmed by a positive culture of M. tuberculosis) and nondefinitive cases (including all other conditions which led to antituberculosis therapy). Secondly, the paper provides an overview of the current surveillance policies in most European countries, which has not been available to the public so far. Thirdly, the report makes a clear

\footnotetext{
*Pneumology I, Section of Infectious Diseases and Immunology, Chest Hospital Heckeshorn, Zum Heckeshorn 33, D-14109 Berlin-Wannsee, Germany.
}

statement about a minimum set of variables required for a survey of the epidemiology of tuberculosis in continental Europe. Finally, the Working Group makes a proposal about how to organize the data flow between responsible doctors and public health authorities.

By so doing, the report of the Working Groups addresses the two main problems to be encountered in any surveillance system. All experience with, for example, acquired immune deficiency syndrome (AIDS) surveillance systems, suggests that it is extremely critical to obtain a basic and comparable set of data from the primary sources, which are normally the doctors in charge of the care of the patients. Since all surveillance systems are dependent on the voluntary co-operation of such doctors, it is essential to have a simple and short questionnaire for notification of a case. In my opinion, the proposed questionnaire included in the report of the Working Group meets this criterion by asking for only 16 items, which, with the exception of one, can be answered easily on the day of starting antituberculosis treatment. This one exception is the question about culture results. Since the duration of a tuberculosis culture depends, beside other circumstances, on the method used, the result is typically not available to the doctor until 2-8 weeks following the start of treatment. Because it is doubtful whether a doctor will carry out the notification process twice, it might be useful to give the address of the mycobacterial laboratory performing the culture on the first reporting form to secure the source of culture results together with the reported case.

Equally important is the data flow between doctors who report patients and the public health authorities. Every surveillance system which does not provide a good feedback to the data sources is bound to fail after some time. Therefore, periodic reports of the national and European data to every single doctor who is involved in the notification process is mandatory for motivation.

Problems not addressed in the report of the Working Group are the technical and financial resources of such a notification system. In some European countries, reporting to a national centre using modern telecommunication systems might be a good choice. However, for poorer countries more conventional systems would have to be implemented. In addition to these technical details, every notification system depends on an adequate financial support. It would not be possible to implement a good surveillance system at a national or even European level without a national surveillance centre in every European country and a European tuberculosis surveillance centre.

Although surveillance systems will cost a lot of money, this seems to be a good investment. For the US, the value 
of a national surveillance system was recently demonstrated, since the good epidemiological data provided by the Centers for Disease Control in Atlanta helped to focus public interest on the re-emergence of tuberculosis, to raise money for tuberculosis control, and to inform physicians about their success in controlling the disease [10]. The surveillance of tuberculosis is a keystone in the control of tuberculosis [11], and the time is now ripe to establish such a system in Europe.

In summary, it can be stated that the Working Group has done its homework in a manner of utmost importance. Now it is up to every single member of the European Respiratory Society to raise public awareness and, thus, to bring pressure to bear on politicians to take steps for setting up a working European tuberculosis surveillance system.

\section{References}

1. Bloom BR, Murray CJL. Tuberculosis: commentary on a re-emergent killer. Science 1992; 257: 1055-1064.

2. Kochi A. The global tuberculosis situation and the new control strategy of the World Health Organization. Tubercle 1991; 72: 1-6.

3. Bates, JH, Stead WW. The history of tuberculosis as a global epidemic. Med Clin North Am 1993; 77: 1205-1217.

4. Reichman LB. The U-shaped curve of concern. Am Rev Respir Dis 1991; 144: 741-742.

5. Tala E. Die Tuberkulosesituation in Europa heute. Pneumologie 1991; 45: 539-541.

6. Raviglione MC, Sudre P, Rieder HL, Spinaci S, Kochi A. Secular trends of tuberculosis in western Europe. Bull WHO 1993; 71: 297-306.

7. Raviglione MC, Rieder HL, Styblo K, Khomenko AG, Esteves K, Kochi A. Tuberculosis trends in eastern Europe and the former USSR. Tuberc Lung Dis 1994; 75: 400-416.

8. Rieder HL, Zellweger JP, Raviglione MC, Keizer ST, Migliore GB. Tuberculosis control and international migration in Europe. Eur Respir J 1994; 7: 1545-1553.

9. Rieder HL, Watson JW, Raviglione MC, et al. Surveillance of tuberculosis in Europe. Eur Respir J 1996; 9: 1097-1104.

10. Centers for Disease Control. Meeting the challenge of multidrug-resistant tuberculosis: summary of a conference. Morb Mortal Weekly Rep 1992; 41: 51-57.

11. World Health Organization. WHO Tuberculosis Programme framework for effective tuberculosis control. Geneva 1994. 